\title{
Special Issue: Slavic Perspectives on Prosody
}

\author{
Zofia Malisz ${ }^{\mathrm{a}} \quad$ Marzena Żygis ${ }^{\mathrm{b}}$ \\ aDepartment of Speech, Music and Hearing, KTH, Stockholm, Sweden; \\ ${ }^{\mathrm{b} C e n t r e ~ f o r ~ G e n e r a l ~ L i n g u i s t i c s ~ a n d ~ H u m b o l d t ~ U n i v e r s i t y, ~ B e r l i n, ~ G e r m a n y ~}$
}

\section{Slavic Prosody}

This special double-issue volume of Phonetica presents papers that analyze a wide range of prosodic phenomena: speech rhythm, timing, prominence and intonation. They cover the communicative and linguistic functions of prosody and their interaction with other domains, e.g., segmental structure, discourse functions and information structure. The focus on Slavic languages, with studies of Polish, Czech, Slovak, Russian and Bulgarian, is a small step towards correcting the relative under-representation of these languages in the recent mainstream prosodic literature. The Slavic language group is one of the three sub-families of Indo-European in Europe with a large number of speakers, the other two being the Germanic and Romance language groups. The Slavic family comprises ca. 12 official languages: Belarusian, Russian, Ukrainian, Czech, Polish, Slovak, Bosnian, Bulgarian, Croatian, Macedonian, Serbian and Slovene and their many sub-dialects, spoken by around 300 million people in geographical Europe alone (Lewis et al., 2014). Within the three sub-branches of Slavic (Eastern, Western and Southern), we find several minority and/or endangered languages, e.g., Rusyn, Kashubian, Lower and Upper Sorbian as well as transitional and insular dialects, e.g., West Polesian (Belarus-Ukraine borderlands), Resian (Italy-Slovenia), Lachian (Czechia-Slovakia-Poland) or Banat Bulgarian (Serbia-Romania) and others (Comrie and Corbett, 2003).

However, given its size, and compared to Germanic and Romance language groups, work on the prosody of Slavic has been relatively rarely reported in high-impact phonetic journals or edited collections that appear in English ${ }^{1}$. To illustrate the current exposure of Slavic prosody research, we provide a rough measure of the scientific output on the topic: a search was conducted (April 28, 2016) with English keywords 'prosody' and the name of each of the official languages in the Slavic, Romance and Germanic families

\footnotetext{
${ }^{1}$ International journals listed on the European Reference Index for Humanities (ERIH) specifically targeting Slavic linguistics, published mainly in English, and with frequently occurring papers on phonetics include, e.g.: Journal of Slavic Linguistics, Russian Linguistics. Other journals on Slavic published both in English and in target languages are listed, e.g. at: http://www.slavistik-portal.de/zeitschriften/zdb.html.
}

\section{KARGER \\ E-Mail karger@karger.com www.karger.com/pho}

Zofia Malisz

Department of Speech, Music and Hearing KTH

SE-10044 Stockholm (Sweden)

E-Mail malisz@kth.se 
via one of the popular search engines that harvest scientific literature. The number of hits was summed for each family: for Slavic, the estimate is ca. 56,700; for Romance, ca. 122,400; and for Germanic 218,950. This means that the output on Slavic prosody constitutes $10-15 \%$ of the sum for the three families (depending on whether or not we normalize by the number of languages in the family).

These data are an indirect consequence of political circumstances in Eastern Europe in the years 1945-1989 and possibly also of traditional divisions of labor among linguistic disciplines (Bethin, 2000). For most of the postwar period, contacts between academics were limited and the penetration of published research on Slavic linguistics on the international stage was weak. The situation was further complicated by the fact that publications were often required to appear primarily in the respective Slavic languages.

This was particularly unfortunate, since the period also witnessed many linguists and entire schools of linguistic thought in Slavic-speaking countries making great progress in phonetics and phonology (see for instance Andreeva et al. (this volume) who points to the Russian Intonation School). However, their achievements have not been as well integrated into the paradigm shifting mainstream as had been the case before the 2nd World War (Anderson, 1985).

One of the consequences of the lower research volume on Slavic phonetics, and particularly prosody, is that major gaps in its description still exist. Research on Slavic segmental phonology on the other hand has been abundant, given its historical dominance over phonetic/prosodic work among Slavic scholars since the Prague School. Segmental studies in Slavic continue to receive attention (palatalization: Kavitskaya (2006); Kochetov (2006, 2013); Ordin (2011); Mitrović (2012), voicing: Strycharczuk (2012); Ringen and Kulikov (2012); Kharlamov (2014), vowel-zero alternations, i.e., yers: Beňuš (2012); Rubach (2013) and references therein, sibilants and sibilant systems: Nowak (2006); Żygis and Padgett (2010); Pastätter and Pouplier (2013); Howson (2015)).

However, only few prosodic aspects of Slavic languages have been considered 'classic' and have regularly generated debates, e.g., issues in Slavic lexical stress systems (see Dogil and Williams (1999); Peperkamp et al. (2010); Newlin-Łukowicz (2012); Domahs et al. (2012) for recent work on Polish stress).

Markedly, the extensive literature on the phonology of Slavic stress and accent (see Halle (2001); Bethin (2006); Kraska-Szlenk (1995) and particularly, the review by Bethin (2000) on post-war Slavic phonology research until the millennium), stands in contrast to relatively rarer work on the acoustic correlates of prominence (lexical and phrasal stress) in Slavic languages (Crosswhite (2003) for Bulgarian, Macedonian and Polish, Malisz and Wagner (2012) for Polish, Gordeeva et al. (2003) for Russian, Duběda and Votrubec (2005) for Czech). Additionally, studies appearing in English that discuss crosslinguistic differences in global timing relations, rhythmic and prominence patterns are frequently forced to refer to few, often outdated sources or nearly empirically unattested observations regarding the particular structures in Slavic.

More attention towards Slavic languages should be warranted by results that challenged established prosodic generalizations or typologies, especially those developed primarily on the basis of Romance and Germanic data. For instance, attempts to show separation between postulated classes in rhythm taxonomies, although generally problematic (Cummins, 2002; Wiget et al., 2010; Arvaniti, 2009), have quickly demonstrated the need for re-evaluation because of Slavic data (Ramus, 
2002): the languages 'fell out' of the parameter space operationalized by, e.g., rhythm metrics or failed to generalize according to trichotomous categories of mora, stress and syllable-timed (see Dankovičová and Dellwo (2007) for Czech, Beňuš and Šimko (2012) for Slovak, Malisz (2013); Wagner (2014); Gibbon et al. (2014) for Polish, Barry et al. (2003) for Bulgarian).

Bethin (2000) noted in her overview of Slavic studies in the U.S. that major paradigm shifts in prosodic phonology, such as the widespread move to autosegmentalmetrical models, have happened without the wider involvement of Slavists. Intonational phonology description systems (ToBI or alternatives) have since been suggested for Slavic languages (Odé (2003); Rathcke (2009, 2013) for Russian, Rusko et al. (2007) for Slovak, Godjevac (2000a, b, 2005) and Smiljanić (2013) for Serbian and Croatian, Wagner (2008) for Polish). However, consolidated or comparative follow-up discussions to these endeavors have not yet taken place.

It is, therefore, not surprising that data from Slavic often sit squarely with mainstream intonation models. The present issue provides an opportunity to re-evaluate the models in light of, for instance, the especially rich linguistic means of expressing information structure in Slavic (Jasinskaja, 2013). Within the Slavic family, we find a lot of differences in how intonation contours in yes/no questions are realized, a degree of variation that is seldom found among the languages in the Germanic family (Sawicka, 2001; Andreeva et al., 2015). Deaccentuation (Cruttenden, 2006) under focus in Slavic also appears to deviate from the regular pattern found in Germanic. One of the most distinctive characteristics of Slavic languages is the free word order which has profound consequences on the syntax-prosody interface (Comrie and Corbett, 2003).

Nonetheless, while some of the major Slavic languages have been described with regards to prosody and information structure (Andreeva and Oliver (2005); Andreeva et al. (2012) for Bulgarian and Polish), others, especially those with a small number of speakers, have no available descriptions at all (Jasinskaja (2013) mentions Slovene and Sorbian). Similarly, research on the functions of prosody in discourse needs more investigation (Karpiński, 2012).

Meanwhile, mainstream research on prosody has been developing strongly in the exploration of segment-prosody interfaces (e.g., issues in Phonetica edited by Kohler (2012) and in the Journal of Phonetics by Mücke et al. (2014)). Evidence recently gained from laboratory phonological research on Slavic languages provided crucial insights into the ways in which prominence and the edges of prosodic constituents influence segmental attributes and conversely, how prosodic properties are contingent upon segmental properties (Iskarous and Kavitskaya, 2010; Malisz et al., 2013; Duběda and Keller, 2005; Pouplier and Beňuš, 2011; Żygis et al., 2014).

Given the status of Slavic prosody studies, the present issue aims to help relieve some of the urgent needs in the description of prosodic phenomena in Slavic, update the state of modeling, and provide a wider linguistic context for an unbiased discussion of the established models in our discipline.

\section{The Special Issue}

To strengthen the position of research on Slavic prosody in modern phonetics, the issue concentrates on bringing those phenomena in Slavic to closer attention that are currently considered crucial in solving critical prosodic problems. Similarly, 
focus is on studies that use up-to-date and established descriptive methodologies and theoretical frameworks enabling the following: comparison of results on Slavic with other languages, extension of existing theories and models to Slavic material, revision of theoretical generalizations and evaluation of the validity of established methods.

The papers are gathered into two sub-topics in the present volume: 'Slavic Prosody' and 'Interfaces in Slavic Prosody', teasing apart work focusing on purely prosodic phenomena and that in which the explanations are based on links to other linguistic representations and areas. Thus, the first sub-topic includes papers which predominantly deal with fundamental problems in Slavic prosody, i.e., timing phenomena, acoustic correlates of prominence, rhythm and intonation (Beňuš and Šimko; Rathcke; Malisz et al.). The second sub-topic encompasses studies which link prosody with other linguistic areas, such as information structure, syntax and pragmatics (Andreeva et al.; Luchkina and Cole; Volín et al.; Arvaniti et al.).

Beňuš and Šimko employ Lombard speech to uncover the phonetic mechanisms of boundary strengthening. By pushing the realization of prosodic boundaries and prominence in Slovak to their limits, they find that realized $f 0$, duration and articulatory patterns are not simply accumulative but reveal complementary synergistic effects based on affordances in noise-unperturbed speech. Although Beňuš and Šimko do not commit to any theory or model in this work, the methodological paradigm harks back to perturbation studies revealing coordination dynamics of complex systems (Kelso and Tuller, 1983), in this case, the dynamics of prosodic patterning.

Languages follow one of two strategies when the timing and voicing of segments structurally constrain the production of pitch accents: the intended pitch contour can be entirely produced in a limited time period and compressed or it can be incompletely realized by undershooting the target and truncating $f 0$ (Erikson and Alstermark, 1972; Grabe, 1998). Rathcke re-analyzes truncation in two typologically different languages, Russian and German and questions the classification of languages as either compressing or truncating (Ladd, 2008) by showing that a given language can follow both strategies. She also proposes a more comprehensive model of tonal adjustment for Russian and German.

Malisz, O'Dell, Nieminen and Wagner propose a dynamic model, the coupled oscillator model (O’Dell and Nieminen, 2009) in the current debate concerning the mechanisms behind speech timing and rhythm. They then explore the coupling of the syllabic oscillator with supra-syllabic oscillators in two typologically different languages, one Slavic (Polish) and one Finno-Ugric (Finnish). They suggest that language specific prosodic constraints determine the identity of the supra-syllabic cycle: the phonological word is more relevant in Polish than in Finnish. Also, they show that the mutual influences between the oscillators change dramatically under different speech rate conditions in Polish but not in Finnish.

Regarding information structure, Andreeva, Koreman and Barry show that Bulgarian speakers consistently differentiate broad and narrow focus by means of both local cues, i.e., those encoded in the nuclear-accented syllables, and global acoustic cues, i.e., those reflecting broader phonetic patterns in the intervals before and after the nuclear-accented syllable. Their results indicate that speakers produce different pitch accent types on the nuclear syllable and reduce the 'phonetic strength' of the default pre-nuclear accent in the narrow focus condition. The acoustic properties of the nuclear and pre-nuclear accented syllables are less pronounced in 
the broad focus condition and considerably more strongly manifested in the narrow focus condition.

The paper by Luchkina and Cole examines structural and referent-based effects in terms of acoustic cues in Russian. While the former effects refer to the particular linearization of words in a sentence, the latter include the semantic and pragmatic effects of the discourse referent of a word, and grammatical roles that are partially dependent on referent characteristics. The results indicate prosodic augmentation in terms of increased F0, intensity and duration due to both structural effects, i.e., words positioned ex-situ, and referent-based effects, i.e., words that are grammatical subjects with animate referents. In addition, it is shown that discourse-given and discourse-new information is prosodically more augmented than inferable information.

Studies in this issue also show how established acoustic parameters co-vary to cue communicative functions in discourse (Volín et al.; Arvaniti et al.) and information structure (Andreeva et al.). Volín, Weingartová and Niebuhr offer an in-depth examination of the prosodic forms that express different pragmatic functions of the Czech discourse marker 'jasně', including resignation, reassurance, surprise, indifference or impatience. Their results point to multi-parametric differences between the 'jasně' realizations in terms of their F0, timing and intensity patterns, which give rise to generally consistent form-function mappings when submitted to a clustering analysis.

Finally, Arvaniti, Żygis and Jaskula examine the intonation of calling in Polish under pragmatic circumstances which lead to two distinct melodies that the authors call 'urgent' and 'routine'. They provide an autosegmental-metrical (AM) analysis for these melodies based on both F0 and other differences, and focus their analysis within a broader consideration of the intonation system of Polish. The authors also address the issue of modeling these melodies in AM, which assumes underspecification in intonation, and the Parallel Encoding and Target Approximation (PENTA, e.g. Xu et al., 2015), which predicts a syllable-by-syllable specification for F0; they show that while AM can adequately model the attested Polish contours even under extreme tonal crowding, this is not possible in PENTA, as full F0 specification does not provide the requisite flexibility (Arvaniti and Ladd, 2009, 2015; Xu et al., 2015).

In almost all papers dealing with intonation, authors either explicitly emphasize or implicitly assume that intonation is not only expressed by the fundamental frequency but is also simultaneously cued by amplitude, duration and spectral properties (Arvaniti et al.; Luchkina and Cole). Similarly, Beňuš and Šimko, who investigate how increasing the level of ambient noise affects the realization of Slovak prosodic boundaries, conclude that all cues, including some articulatory parameters, 'co-create complex prosodic patterns in a complementary and synergetic manner'. Andreeva et al. address the question of how different types of focus in Bulgarian (broad vs. narrow, non-contrastive and contrastive) are acoustically distinguished and defined by means of pitch, duration and intensity variation.

The authors of the special issue highlight the importance of a more structurally complex point of view on the phenomena by describing several levels of relationships between the prosodic units narrowing and widening the scope of analysis. Andreeva et al. describe local lengthening under paradigmatic focus in Bulgarian but also the relative syntagmatic suppression of prominence in the pre-nuclear syllables leading to increased salience of the accented material in narrow focus. Similarly, Beňuš and Šimko study the phonetic adjustments speakers make in adverse conditions on several 
boundary levels and also examine the relationships of prominence (pitch accents) and boundary cues. Luchkina and Cole exploit the fact that Russian is characterized by free word order to investigate syntagmatic prosodic relations in whole utterances.

Analyses of both laboratory and quasi-spontaneous speech material are included, especially studies that combine both corpus-analytic and experimental methods. Such diversity is welcome given a current debate on the impact of stylistic diversity in phonetic and phonological research (Wagner et al., 2015) vs. advantages of using controlled data $(\mathrm{Xu}, 2010)$. The results presented in the special issue are based on analyses of strictly controlled data (Andreeva et al.; Arvaniti et al.; Beňuš and Šimko; Rathcke), quasi-spontaneous speech data based on scripted dialogues (Volín et al.) and read speech (Malisz et al.; Luchkina and Cole).

Finally, it is also notable that in the majority of studies in this issue much emphasis has been put on inter-speaker variation, its potential sources and consequences for the analysis.

We believe that this collection of studies on Slavic prosody provides a platform for some of the current, high quality phonetic research on Slavic prosody and serves as a valuable reference for future investigations. Our hope is also that a renewed interest in Slavic prosodic systems will be beneficial in drawing more attention not only to the major languages but also to lesser known and minority languages and dialects in Slavic that definitely deserve more scientific attention.

\section{Acknowledgements}

We would like to thank the main editor Catherine Best and the associate editor William Barry for keeping a watchful eye on the development of the issue, the authors for their contributions, the reviewers, as well as colleagues, Irena Sawicka and Roland Marti for their advice. We would also like to thank the participants of the special session on Slavic prosody at the 2014 Speech Prosody conference in Dublin where early versions of the contributions to the present issue were presented.

This work has been supported by Bundesministerium für Bildung und Forschung (BMBF, Germany) Grant No. 241 01UG1411 to Marzena Żygis and by the German Research Foundation (DFG) as part of SFB 1102 'Information Density and Linguistic Encoding' at Saarland University.

\section{References}

Anderson SR (1985): Phonology in the twentieth century: theories of rules and theories of representations. Chicago, University of Chicago Press.

Andreeva B, Barry W, Wolska M (2012): Language differences in the perceptual weight of prominence-lending properties; in Proceedings of INTERSPEECH 2012, Portland, OR. International Speech Communication Association, pp 2426-2429.

Andreeva B, Koreman J, Barry W (this volume): Local and global cues in the prosodic realization of broad and narrow focus in Bulgarian. Phonetica.

Andreeva B, Möbius B, Demenko G, Zimmerer F, Jügler J (2015): Linguistic measures of pitch range in Slavic and Germanic languages; in Proceedings of INTERSPEECH 2015, Dresden. International Speech Communication Association, pp 968-972.

Andreeva B, Oliver D (2005): Information structure in Polish and Bulgarian: accent types and peak alignment in broad and narrow focus. Formal Approaches Slavic Linguist 13:1-13.

Arvaniti A (2009): Rhythm, timing and the timing of rhythm. Phonetica 66:46-63.

Arvaniti A, Ladd DR (2009): Greek wh-question and the phonology of intonation. Phonology 26:43-74. 
Arvaniti A, Ladd RD (2015): Underspecification in intonation revisited: a reply to Xu, Lee, Prom-on and Liu. Phonology 32:537-541.

Arvaniti A, Żygis M, Jaskuła M (this volume): The phonetics and phonology of Polish calling melodies. Phonetica.

Barry WJ, Andreeva B, Russo M, Dimitrova S, Kostadinova T, et al (2003): Do rhythm measures tell us anything about language type? Proceedings of the 15th International Congress of Phonetic Sciences, Barcelona, pp 2693-2696.

Beňuš Š (2012): Phonetic variation in Slovak yer and non-yer vowels. J Phonet 40:535-549.

Beňuš Š, Šimko J (2012): Rhythm and tempo in Slovak. Proceedings of the 6th International Conference on Speech Prosody, Chicago, pp 502-505.

Beňuš Š, Šimko J (this volume): Stability and variability in Slovak prosodic boundaries. Phonetica.

Bethin CY (2000): Slavic phonology in the United States. SLING2K Workshop Position Paper. http://www.indiana. edu/ slavconf/SLING2K/pospapers/bethin.pdf.

Bethin CY (2006): Stress and tone in East Slavic dialects. Phonology 23:125-156.

Comrie B, Corbett G (2003): The Slavonic Languages. Abingdon, Routledge.

Crosswhite K (2003): Spectral tilt as a cue to stress in Polish, Macedonian and Bulgarian. Proceedings of the 15th International Congress of Phonetic Sciences, Barcelona, pp 767-770.

Cruttenden A (2006): The de-accenting of given information: a cognitive universal? Empir Approaches Language Typol 20:311.

Cummins F (2002): Speech rhythm and rhythmic taxonomy. Proceedings of the 1st International Conference on Speech Prosody, Aix-en-Provence, pp 121-126.

Dankovičová J, Dellwo V (2007): Czech speech rhythm and the rhythm class hypothesis. Proceedings of the 16th International Congress of Phonetic Sciences, Saarbrücken, pp 1241-1244.

Dogil G, Williams B (1999): The phonetic manifestation of word stress; in van der Hulst H (ed): Word Prosodic Systems in the Languages of Europe. Berlin, Mouton de Gruyter, pp 273-311.

Domahs U, Knaus J, Orzechowska P, Wiese R (2012): Stress deafness in a language with fixed word stress: an ERP study on Polish. Front Psychol 3:1-15.

Duběda T, Keller E (2005): Microprosodic aspects of vowel dynamics - an acoustic study of French, English and Czech. J Phonet 33:447-464.

Duběda T, Votrubec J (2005): Acoustic analysis of Czech stress: intonation, duration and intensity revisited; in Proceedings of INTERSPEECH 2005, Lisbon. International Speech Communication Association, pp 14291432.

Erikson Y, Alstermark M (1972): Fundamental frequency correlates of the grave word accent in Swedish: the effect of vowel duration. Speech Transm Lab Q Papers Status Rep, pp 2-3.

Gibbon D, Klessa K, Bachan J (2014): Duration and speed of speech events: a selection of methods. Lingua Posnaniensis 56:59-83.

Godjevac S (2000a): An Autosegmental/Metrical Analysis of Serbo-Croatian Intonation. Working Papers in Linguistics. Columbus, Ohio State University Department of Linguistics, pp 79-142.

Godjevac S (2000b): Intonation, Word Order and Focus Projection in Serbo-Croatian; PhD thesis, Ohio State University, Columbus.

Godjevac S (2005): Transcribing Serbo-Croatian Intonation. Oxford, Oxford University Press, pp 146-171.

Gordeeva O, Mennen I, Scobbie JM (2003): Vowel duration and spectral balance in Scottish English and Russian. Proceedings of the 15th International Congress of Phonetic Sciences, Barcelona, pp 3193-3196.

Grabe E (1998): Pitch accent realization in English and German. J Phonet 26:129-143.

Halle M (2001): On accent, stress and quantity in West Slavic. Lingua 111:791-810.

Howson P (2015): An acoustic examination of the three-way sibilant contrast in Lower Sorbian; in Proceedings of INTERSPEECH 2015, Dresden. International Speech Communication Association, pp 2670-2674.

Iskarous K, Kavitskaya D (2010): The interaction between contrast, prosody, and coarticulation in structuring phonetic variability. J Phonet 38:625-639.

Jasinskaja K (2013): Information structure in Slavic; in Féry C, Ishihara S (eds): OUP Handbook of Information Structure. Oxford, Oxford University Press.

Karpiński M (2012): Acoustic properties and functions of phrase-final rises in Polish task oriented dialogues. Speech Lang Technol 14/15:147-156.

Kavitskaya D (2006): Perceptual salience and palatalization in Russian. Lab Phonol 8:589-610.

Kelso JS, Tuller B (1983): Compensatory articulation under conditions of reduced afferent information: a dynamic formulation. J Speech Lang Hear Res 26:217-224.

Kharlamov V (2014): Incomplete neutralization of the voicing contrast in wordfinal obstruents in Russian: phonological, lexical, and methodological influences. J Phonet 43:47-56.

Kochetov A (2006): Testing licensing by cue: a case of Russian palatalized coronals. Phonetica 63:113-148.

Kochetov A (2013): Production, Perception, and Phonotactic Patterns: A Case of Contrastive Palatalization. Abingdon, Routledge.

Kohler KJ (2012): Bridging the segment-prosody divide in speech production and perception. Phonetica 69:56.

Kraska-Szlenk I (1995): The Phonology of Stress in Polish; PhD thesis, University of Illinois at Urbana-Champaign.

Ladd DR (2008): Intonational Phonology. Cambridge, Cambridge University Press. 
Lewis MP, Simons GF, Fennig CD (eds) (2014): Ethnologue: Languages of the World, ed 17. Dallas, SIL International.

Luchkina T, Cole J, (this volume): Structural and referent-based effects on prosodic expression in Russian. Phonetica.

Malisz Z (2013): Speech Rhythm Variability in Polish and English: A Study of Interaction between Rhythmic Levels; PhD thesis, Adam Mickiewicz University, Poznań.

Malisz Z, O'Dell M, Nieminen T, Wagner P (this volume): Modeling the speech rhythm of Polish with coupled oscillators. Phonetica.

Malisz Z, Wagner P (2012): Acoustic-phonetic realisation of Polish syllable prominence: a corpus study. Speech Lang Technol 14/15:105-114.

Malisz Z, Żygis M, Pompino-Marschall B (2013): Rhythmic structure effects on glottalisation: a study of different speech styles in Polish and German. Lab Phonol 4:119-158.

Mitrovič I (2012): A phonetically natural vs native language pattern: an experimental study of velar palatalization in Serbian. J Slavic Linguist 20:229-268.

Mücke D, Grice M, Cho T (2014): More than a magic moment - paving the way for dynamics of articulation and prosodic structure. J Phonet 44:1-7.

Newlin-Łukowicz L (2012): Polish stress: looking for phonetic evidence of a bidirectional system. Phonology 29:271-329.

Nowak P (2006): The role of vowel transitions and frication noise in the perception of Polish sibilants. J Phonet 34:139-152.

Odé C (2003): Description and transcription of Russian intonation (ToRI). Stud Slavic Gen Linguist 30:279-288.

O'Dell ML, Nieminen T (2009): Coupled oscillator model for speech timing: overview and examples; in Nordic Prosody: Proceedings of the 10th Conference. Helsinki, Lang, pp 179-190.

Ordin M (2011): Palatalization and intrinsic prosodic vowel features in Russian. Lang Speech 54:547-568.

Pastätter M, Pouplier M (2013): Temporal coordination of sibilants in Polish onset clusters. J Acoust Soc Am 134:4201.

Peperkamp S, Vendelin I, Dupoux E (2010): Perception of predictable stress: a cross-linguistic investigation. J Phonet 38:422-430.

Pouplier M, Beňuš S̆ (2011): On the phonetic status of syllabic consonants: evidence from Slovak. Lab Phonol $2: 243-273$.

Ramus F (2002): Acoustic correlates of linguistic rhythm: perspectives. Proceedings of the 1st International Conference on Speech Prosody, Aix-en-Provence, pp 115-120.

Rathcke T (2013): On the neutralizing status of truncation in intonation: a perception study of boundary tones in German and Russian. J Phonet 41:172-185.

Rathcke TV (2009): Komparative Phonetik und Phonologie der Intonationssysteme des Deutschen und Russischen. Munich, Utz, vol. 29.

Rathcke TV (this volume): How truncating are 'truncating languages': evidence from Russian and German. Phonetica.

Ringen C, Kulikov V (2012): Voicing in Russian stops: cross-linguistic implications. J Slavic Linguist 20:269-286

Rubach J (2013): Exceptional segments in Polish. Nat Lang Linguist Theory 31:1139-1162.

Rusko M, Sabo R, Dzúr M (2007): Sk-ToBI scheme for phonological prosody annotation in Slovak; in Král P, Matoušek V (eds): Text, Speech and Dialogue. Berlin, Springer, pp 334-341.

Sawicka I (2001): An Outline of the Phonetic Typology of the Slavic Languages. Torun, Wydawnictwo Uniwersytetu M. Kopernika.

Smiljanić R (2013): Lexical, Pragmatic, and Positional Effects on Prosody in Two Dialects of Croatian and Serbian: An Acoustic Study. Abingdon, Routledge.

Strycharczuk P (2012): Sonorant transparency and the complexity of voicing in Polish. J Phonet 40:655-671.

Volín J, Weingartová L, Niebuhr O (this volume): The prosody of the Czech discourse marker 'jasně': an analysis of forms and functions. Phonetica.

Wagner A (2008): A Comprehensive Model of Intonation for Application in Speech Synthesis; PhD thesis, Adam Mickiewicz University, Poznań.

Wagner A (2014): Description of Polish speech rhythm using rhythm metrics and the time-delay approach: a comparative study. Proceedings of the 7th International Conference on Speech Prosody, Dublin, pp 366-370.

Wagner P, Trouvain J, Zimmerer F (2015): In defense of stylistic diversity in speech research. J Phonet 48:1-12.

Wiget L, White L, Schuppler B, Grenon I, Rauch O, Mattys SL (2010): How stable are acoustic metrics of contrastive speech rhythm? J Acoust Soc Am 127:1559-1569.

Xu Y (2010): In defense of lab speech. J Phonet 38:329-336.

Xu Y, Lee A, Prom-on S, Liu F (2015): Explaining the PENTA model: a reply to Arvaniti and Ladd. Phonology 32:505-535.

Żygis M, Padgett J (2010): A perceptual study of Polish fricatives, and its implications for historical sound change. J Phonet 38:207-226.

Żygis M, Pape D, Jesus LM, Jaskuła M (2014): Intended intonation of statement and polar questions in Polish whispered, semi-whispered and normal speech modes. Proceedings of the 7th International Conference on Speech Prosody, Dublin, pp 678-682. 